\title{
Attention, predictions and expectations, and their violation: attentional control in the human brain
}

\author{
Simone Vossel ${ }^{1,2 *}$, Joy J. Geng ${ }^{3}$ and Karl J. Friston ${ }^{1}$ \\ ${ }^{1}$ Wellcome Trust Centre for Neuroimaging, University College London, London, UK \\ 2 Cognitive Neuroscience, Institute of Neuroscience and Medicine (INM-3), Research Centre Jülich, Jülich, Germany \\ ${ }^{3}$ Department of Psychology, Center for Mind and Brain, University of California Davis, Davis, USA \\ ${ }^{*}$ Correspondence: s.vossel@fz-juelich.de
}

Edited and reviewed by:

John J. Foxe, Albert Einstein College of Medicine, USA

Keywords: attentional networks, predictions, trial history, reward, emotions, neuroimaging, TMS, EEG

In the complex scenes of everyday life, our brains must select from among many competing inputs for perceptual synthesisso that only the most relevant are fully processed and irrelevant (distracting) information is suppressed. At the same time, we must remain responsive to salient events outside our current focus of attention-and balancing these two processing modes is a fundamental task our brain constantly needs to solve.

This Research Topic examines how attentional control is guided by sensory predictions, prior knowledge, reward, task sets, and emotional factors. Moreover, the neural signatures of these mechanisms are investigated in Original Research Articles or summarized in Review, Perspective and Hypothesis and Theory Articles. Findings from a wide range of state-of-the-art complementary neuroscientific methods such as fMRI, M/EEG, TMS, and ALE-based meta-analysis are presented.

The collection of papers of this Research Topic provides an overview over our current knowledge in the field and also presents novel stimulating hypotheses on how attention is controlled in the human brain. It moreover bridges the gap to other disciplines such as decision-making and social and affective neuroscience.

Conflict of Interest Statement: The authors declare that the research was conducted in the absence of any commercial or financial relationships that could be construed as a potential conflict of interest.

Received: 15 May 2014; accepted: 17 June 2014; published online: 02 July 2014. Citation: Vossel S, Geng JJ and Friston KJ (2014) Attention, predictions and expectations, and their violation: attentional control in the human brain. Front. Hum. Neurosci. 8:490. doi: 10.3389/fnhum.2014.00490

This article was submitted to the journal Frontiers in Human Neuroscience.

Copyright $\odot 2014$ Vossel, Geng and Friston. This is an open-access article distributed under the terms of the Creative Commons Attribution License (CC BY). The use, distribution or reproduction in other forums is permitted, provided the original author(s) or licensor are credited and that the original publication in this journal is cited, in accordance with accepted academic practice. No use, distribution or reproduction is permitted which does not comply with these terms. 